\title{
The fabrication and application of parametric inflatable structure
}

\section{SIGRADI2018 TECHNOPOLITICAS \\ xxii congresso da sociedade iberoamericana de gráfica digital 22th conference of the iberoamerican society of digital graphics 07|08|09|novembro|2018 iau usp | são carlos | sp br}

\author{
Hsu Yi Chia \\ National Chiao Tung University Institute of Architecture | Taiwan (R.O.C.) | \\ jack_shutw@arch.nctu.edu.tw \\ Hsu Pei Hsien \\ National Chiao Tung University Institute of Architecture | Taiwan(R.O.C.) | \\ phsu@arch.nctu.edu.tw
}

\begin{abstract}
This study uses parametric design to optimize the process and application of the inflatable method. Inflatable design has advantages of light weight, integral forming, volume change, etc., but the manufacturing process often requires the development of molds, a large number of manual heat seals, etc. Inspired by the structure principle of amputated wing tube structure, coupled with the advantages of parameterization and digital tool heat sealing, The same material can be made at different tightness, because the tight design with different angles has more structural characteristics and bending properties, thereby generating more complex spatial structures. Different materials also have corresponding manufacturing methods, which also increase the opportunities for application in architectural design.
\end{abstract}

Keywords: Robotic arms fabrication; Inflatable Shape-change; pneumatic; bending mechanism; pavilion design;

\section{INTRODUCTION}

Inflatable structural applications have been developed for a long time in the construction or manufacturing field, but limited by the mold and airtight material style, often only simple geometry or unable to create complex inflation paths.

Some insects in the arthropod have a hard shell on their wings, while inside they are soft and covered uninflated wings. The outer wings are protected and the inner wings are used for flight.

Once the worm body is about to take off, it will first open the hard exoskeleton wings, and then fill the soft wings contained in it immediately into the body fluid in a short time, and the coherent cavity will be filled from coarse to fine by the designed pipeline. When full, these paths will become the structural skeleton of the entire soft-winged wing surface, and the same material without the inner fin wing of the pipeline will become the airfoil.

Because different insects have different body shapes and wind resistance shapes and even different structures, the path planning on the soft wings will be different. The way to fill the body fluid in a short time will be different from the force part of the structure.

According to the research of insect wings and the results of the paper, the main direction of this research is how to use parametric manufacturing methods.
To efficiently plan the inflation path and the closed path, and find the optimal method corresponding to different materials to manufacture the aeration unit.

\section{METHODOLOGY}

At the beginning of the experiment, this study focuses on three major items. The first step is to find materials that could be inflated. The second is to consider how the material is processed, and the third is to consider whether it is a stable inflation.

\section{INFLATABLE MATERIALS RESEARCH}

In the experiment, first look for aerated, non-extensible materials and try various plastic materials and different thicknesses. The second step is to optimize the processing method and use parametric software to help analyze the model data and manufacturing. A three-axis laser cutter and a six-axis robotic arm with heated metal tool heads are used for programming, not the previous one. A costly manufacturing method is using a manual molding machine or a metal mold. Finally, in order to achieve the design application, different angles and loads formed by the airtight joint portions are studied and recorded after the actual manufacturing unit and inflation.

At the beginning, using PE materials, various thicknesses and widely are used in various domestic products. From the plastic bags for food to the covers packing the entire ship, the materials are made of different thicknesses. 

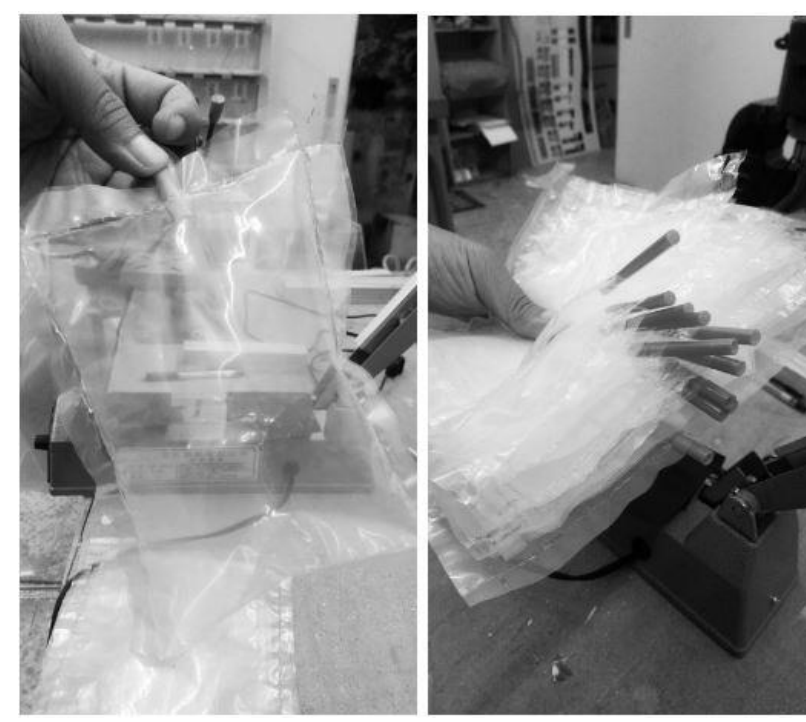

Figure 1: the PE material test with different layers. Source: authors.

To choose two thicknesses, one is 0.5 and $1.5 \mathrm{~mm}$, and use different processing hot pressing methods test the manufacturing process of the sealing unit. (Figure 1)

\section{MATERIAL MANUFACTURING AND PROCESSING}

In view of the fact that plastic is a flat material, it is necessary to use heat sealing to create an inflatable part and a non-inflatable part, so the material processing part is divided into three types. The first one is a hand-press type heat sealing machine. The second is to use a threeaxis laser cutting machine, and the third is to use a sixaxis robotic arm with a heated metal tool head. The three processing methods and processes are recorded below:

\section{[1] HAND-PRESS HEAT SEALING MACHINE}

The hand-press type heat sealing machine has a similar appearance to the stapler to clamp the object under pressure. The principle is that the upper and lower clamps are energized to generate high heat, and the pressed object is heated and melted and sealed.

Because a hot press can only produce a linear seal line, it can only be used for the sealing of the geometric side. Because of this limitation, the initial test uses the PE plastic film of different thickness and layer thickness to exchange hot pressing. Forming inflatable units create of different thicknesses. (Figure 2)

However, this is not only impossible to produce effectively, but also cannot create more styling challenges. Therefore, the heat-insulating tape that is often used in 3D printers is attached to both ends of the heat-sealing machine. This way, the heat source can be insulated, so when the machine is pressed a relatively short heat seal line is formed, and even by controlling the heat insulating tape of different lengths, a broken heat seal line, such as a broken line, can be created.

Such a new heat seal line pattern is formed not only to create a heat seal line in the middle of each of the gas filled units, but also to form an inflatable zone in the middle, or to form a break at the edge of each heat seal end. (Figure 3) The air pressure pipe can be inserted, which can add or subtract air pressure to each unit, and

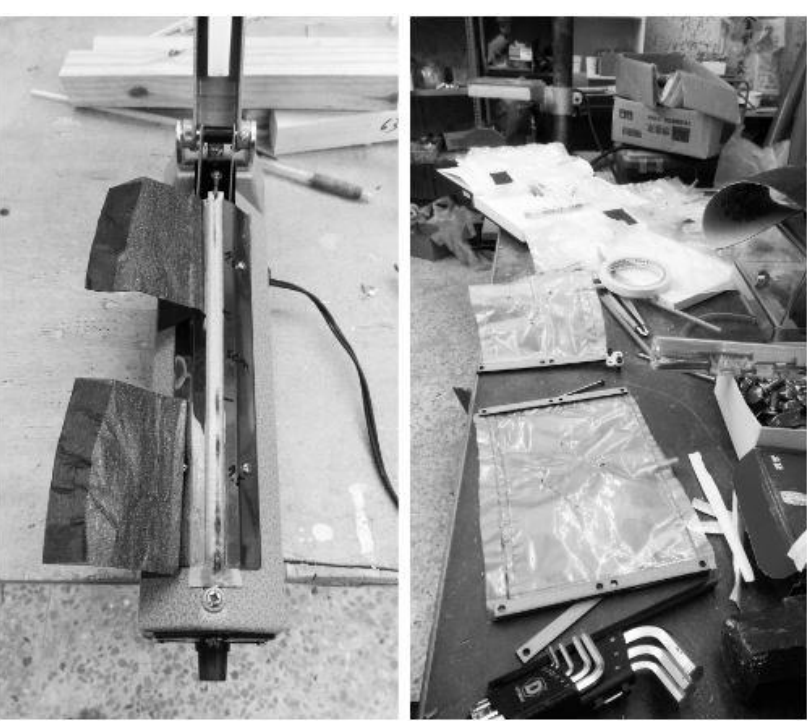

Figure2: using hand-press heat sealing machine to create different pattern and unit. Source: authors.

even connect in series to form an inflatable unit surface design. (Figure 4)

\section{[2] THREE-AXIS LASER CUTTING MACHINE (CNC)}

The first type of hand-press heat sealing machine can only process the size unit within the length of the heat sealer. If it is to create a longer heat seal line, or even an irregular curve break, the lines are very difficult even a parameterized heat seal.

Therefore, we must first find a processing method that can move freely in the XY plane space. It is known that CNC is a processing tool that can gather energy and can blow metal. The principle that he uses is energy gathering or diffusion. So try to use laser cutting machine to cut PE plastic plane and stack two layers of PE plastic plane. On the cutting table, and enter the cut path that has been designed. (Figure 5)

At the beginning, at $100 \%$ power and speed, the first thermal melting point immediately melted the entire material by $1 / 6$, and after that, the power and speed were adjusted to $2 \%$. The cut line is designed with good lines.

Next, try to defocus the heated laser nozzle by $1 \mathrm{~cm}$. The result is amazing. Each of the designed heat seal lines is accurately staked on the PE plane. Under such a result, the layer is divided into two levels, one is output in a state where the power speed is $2 \%$, and the other is operated in a state of defocusing, so that a heat seal line can be created, combined with the cutting line. Inflated unit finished.

This method can accurately and pre-design various paths for cutting, in the test of each inflating unit, it is started to try to cut the middle airtight space with various totems and different angles of geometry, and the difference was observed after the inflation. (Figure 6)

After designing, different angles make different characteristics and structure angles. Because of the accuracy of heating line, It is easy to get the data of heating manufacturing result (Table1) and works. (Figure 7) 


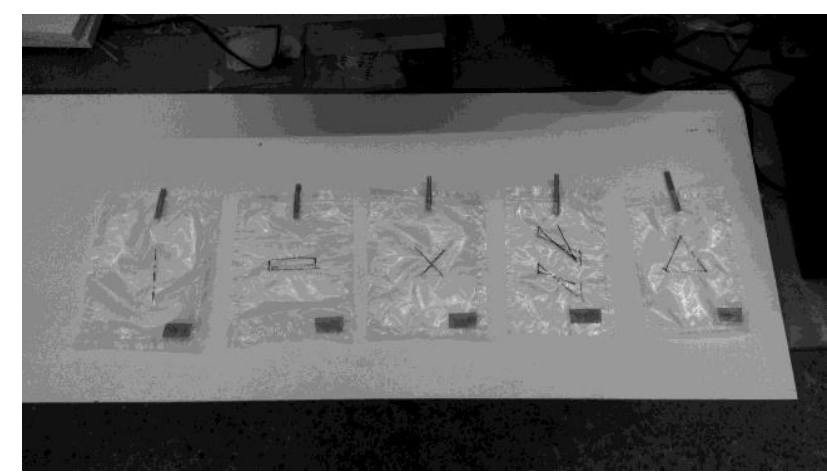

Figure 3: made by hand-press heat sealing machine, different pattern in the middle. Source: authors.

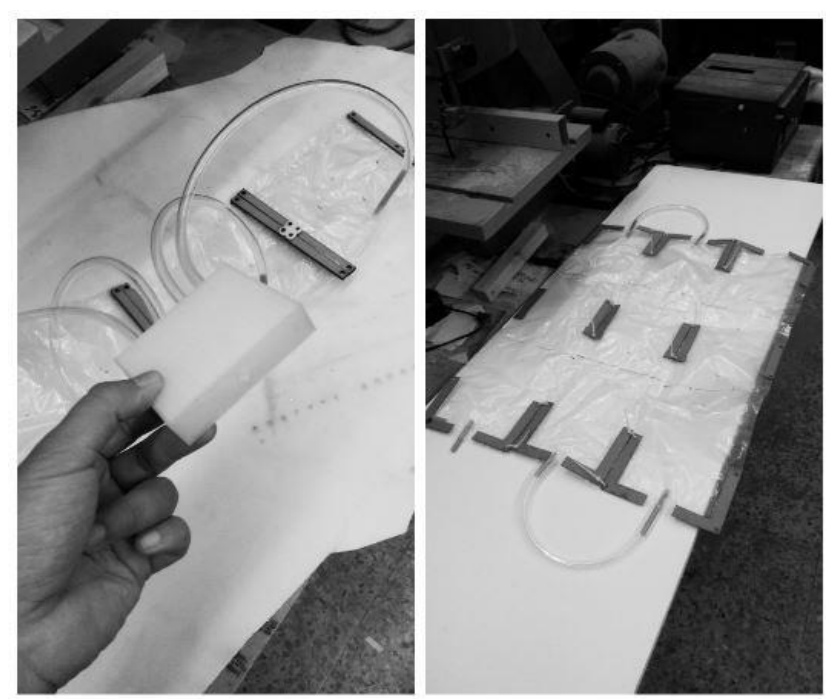

Figure 4: Different inflating units in series and in parallel. Source: authors.

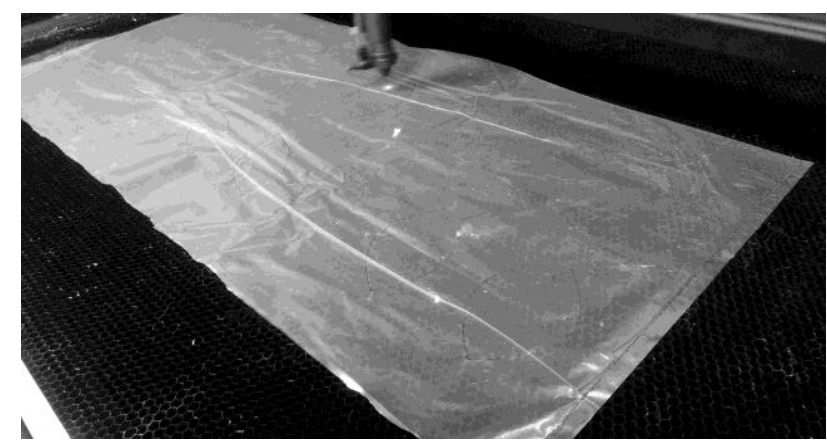

Figure 5: Parametric path produced by using a CNC. Source: authors.

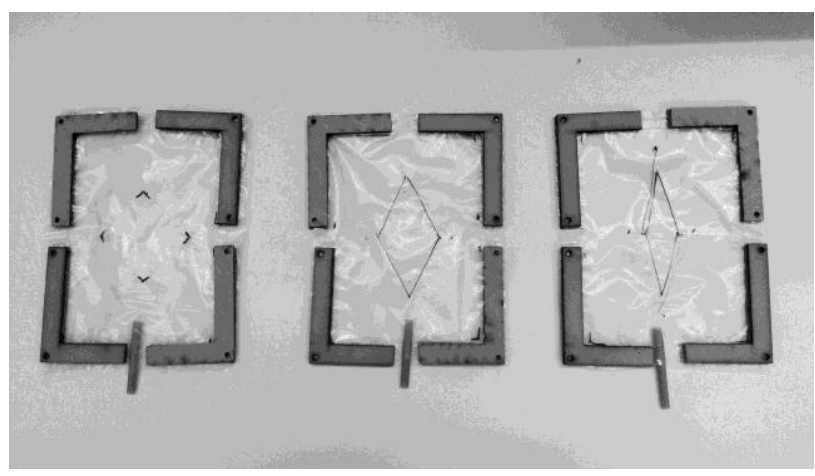

Figure 6: Use a CNC to produce a more precise sealing path to test the angular change after inflation. Source: authors.

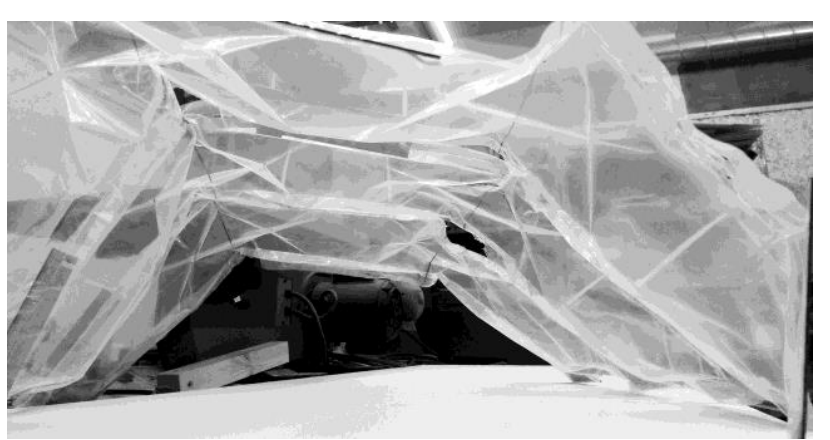

Figure 7: after inflation of the all units by $\mathrm{CNC}$ to produce Source: authors.

Table 1: The characteristic of the unit with different degrees.

\begin{tabular}{|l|l|l|l|}
\hline $\begin{array}{l}\text { The degree of } \\
\text { central block }\end{array}$ & $\begin{array}{l}90 \\
\text { degree }\end{array}$ & $\begin{array}{l}60 \\
\text { degree }\end{array}$ & $\begin{array}{l}30 \\
\text { degree }\end{array}$ \\
\hline $\begin{array}{l}\text { The angle of } \\
\text { bending }\end{array}$ & $\begin{array}{l}90 \\
\text { degree }\end{array}$ & $\begin{array}{l}120 \\
\text { degree }\end{array}$ & $\begin{array}{l}150 \\
\text { degree }\end{array}$ \\
\hline $\begin{array}{l}\text { The rank of weight } \\
\text { load }\end{array}$ & First & Second & Third \\
\hline $\begin{array}{l}\text { The rank of } \\
\text { Inflation time }\end{array}$ & Third & Second & First \\
\hline
\end{tabular}

\section{[3] SIX-AXIS ROBOTIC ARM WITH A HEATED METAL TOOL HEAD}

Basically, after the success of the second heat sealing method, many different units have been produced and tested, and all have good data.

However, if it is necessary to machine a three-dimensional surface today, and this surface is not easily divided and laid out on a flat machine, it is thought to use a 6-axis arm to help manufacturing.

There are several steps that must be taken step by step under this method. The first is about the design of the tool head. The arm is just a precise tool. It can accurately stake the coordinates and path in three-dimensional space, but he must have a machine tool head. The heatwelding iron gun is used as the base, and the heating system is fixed to the metal circular punch commonly used for processing the metal plate by the metal parts, so that the heating temperature can be controlled at the same time, and whether the hot-melt plastic is formed into the heat-sealing line can be determined. Combine more precise control and heat seal segments.

Then there is the planning of the path. Manipulating the robotic arm is a very complicated and complicated process. With the help of the software of Grasshopper, it is very visual, efficient editing path and parameterized lofting (Figure 8).

The third step is to make auxiliary equipment. In the digital manufacturing, with the aid of the arm tool, the auxiliary tool is almost a set of design and process planning with the tool head, and the PE auxiliary tool is manufactured by the stamping adsorption molding method. Another point that helps the tool head can support in threedimensional space. 


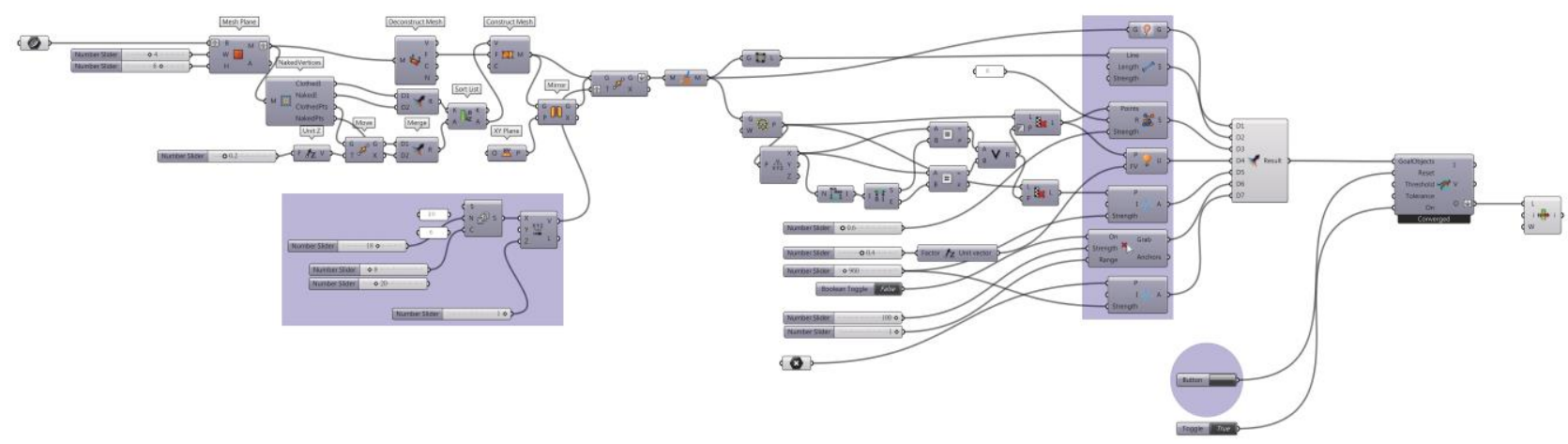

Figure 8: grasshopper can create parameterized path easily. Source: authors.
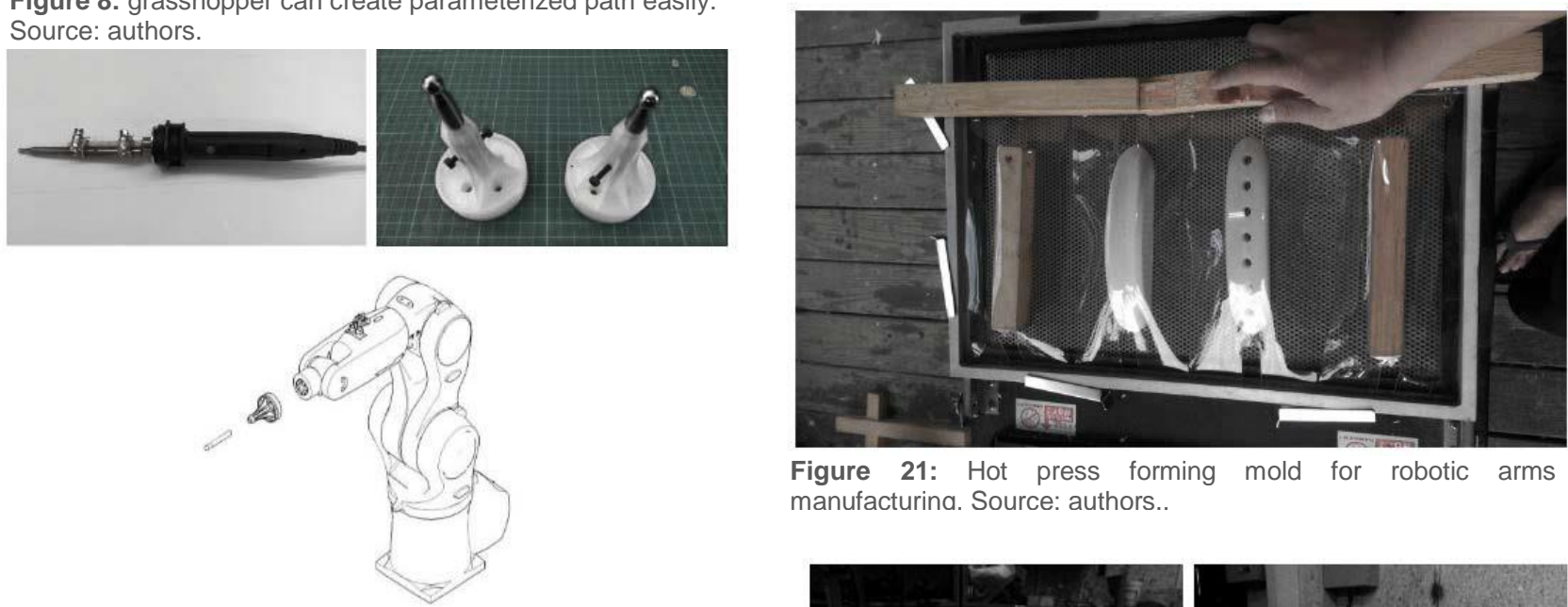

Figure 21: Hot press forming mold for robotic arms manufacturina. Source: authors.

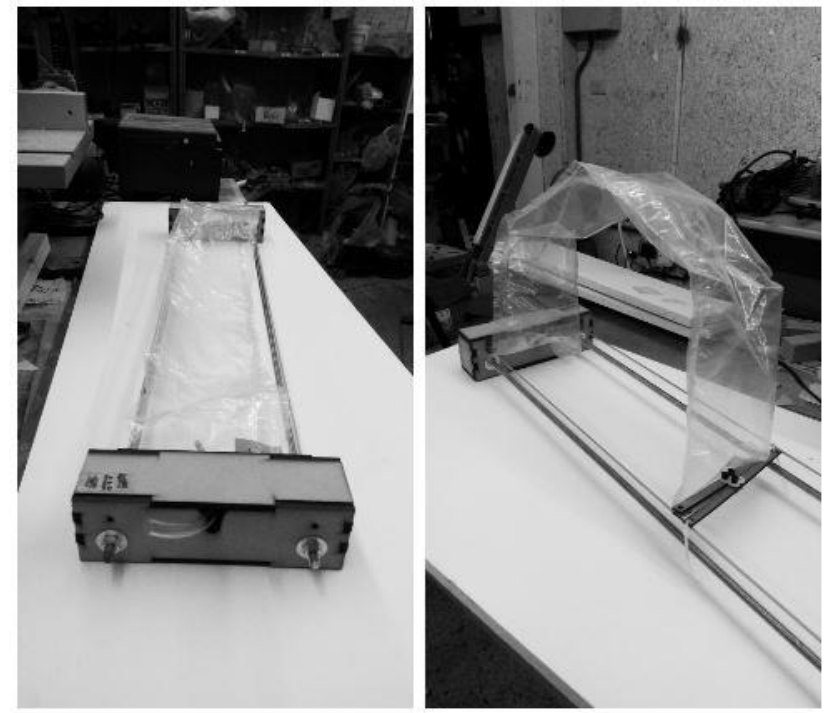

Figure 32: Parameterized digital manufacturing of inflatable unit. Source: authors.

Figure 10: Use robotic arm to produce a more precise sealing path in 3D heating to test the angular change after inflation. Source: authors.

When using a metal circular punch, it can have a fulcrum, and a continuous heat-sealing line can be obtained to achieve a three-dimensional curved heat seal forming unit (Figure 9).

\section{STATUS OF THE MATERIAL AFTER INFLATION}

After the above three methods of manufacturing the inflatable unit, there are some items to be tested, the first is the edge state of the inflatable unit (Figure 10), and the angle of the different inflated area planning in the middle of each inflatable unit or other phenomena record (Figure 11) (Figure 12).

\section{RESULTS}

As a result of this research (Table2), different methods have different limitations. Although it is possible to produce different scales or special aeration units, the efficiency is different when processing different materials or different path designs.

From the unified thumbnail, it can be found that the handtype heat sealing machine can produce the continuous unit accurately and quickly under the small-scale inflatable unit.

In the processing of different angles or curves, it is necessary to use the software planning design path to generate the GCODE for the machine operation to 
operate the path, and in the efficiency and accuracy of the $X Y$ plane processing, the second out-of-focus CNC cutting is used. The way is the most efficient way to mass produce totems with different aerated styles, and is the main method used in the production of the final structure. (Figure 13)

The timing of the third use is quite special. If it is a large flat plastic material or a path that is not a threedimensional curved surface, basically the second processing method is selected, but if it is to be in the inflated unit in the post-production path. With the heat seal line totem, using a robotic arm would be a good choice(Figure 14).

Table 2: The characteristic of different manufacturing process.

\begin{tabular}{|c|c|c|c|c|}
\hline & $\begin{array}{l}\text { manual } \\
\text { heat } \\
\text { sealing in } \\
\text { factory }\end{array}$ & $\begin{array}{l}\text { Manual } \\
\text { heating } \\
\text { machine }\end{array}$ & $\mathrm{CNC}$ & $\begin{array}{l}\text { Robotic } \\
\text { arms with } \\
\text { heating } \\
\text { tool-head }\end{array}$ \\
\hline Advantages & $\begin{array}{l}\text { Molding } \\
\text { and } \\
\text { efficient }\end{array}$ & $\begin{array}{l}\text { Easy to } \\
\text { adjust } \\
\text { and } \\
\text { create } \\
\text { freely }\end{array}$ & $\begin{array}{l}\text { Easy to } \\
\text { paramete } \\
\text { rize and } \\
\text { mass } \\
\text { efficient } \\
\text { productio } \\
n\end{array}$ & $\begin{array}{l}\text { Parameter } \\
\text { ize easily }\end{array}$ \\
\hline $\begin{array}{l}\text { Disadvantag } \\
\text { es }\end{array}$ & $\begin{array}{l}\text { Not easy } \\
\text { to adjust } \\
\text { and } \\
\text { paramete } \\
\text { rize }\end{array}$ & $\begin{array}{l}\text { Not easy } \\
\text { to } \\
\text { paramete } \\
\text { rize }\end{array}$ & $\begin{array}{l}\text { Take } \\
\text { time to } \\
\text { coding or } \\
\text { drawing, } \\
\text { but easy } \\
\text { than } \\
\text { Robotic } \\
\text { arms }\end{array}$ & $\begin{array}{l}\text { Take time } \\
\text { to coding } \\
\text { and } \\
\text { design the } \\
\text { tool and } \\
\text { manufactu } \\
\text { ring } \\
\text { method }\end{array}$ \\
\hline $\begin{array}{l}\text { Parameteriz } \\
\text { ation }\end{array}$ & $\begin{array}{l}\text { Need to } \\
\text { take lot of } \\
\text { time and } \\
\text { money }\end{array}$ & $\begin{array}{l}\text { Need to } \\
\text { take lot of } \\
\text { time }\end{array}$ & easy & easy \\
\hline
\end{tabular}

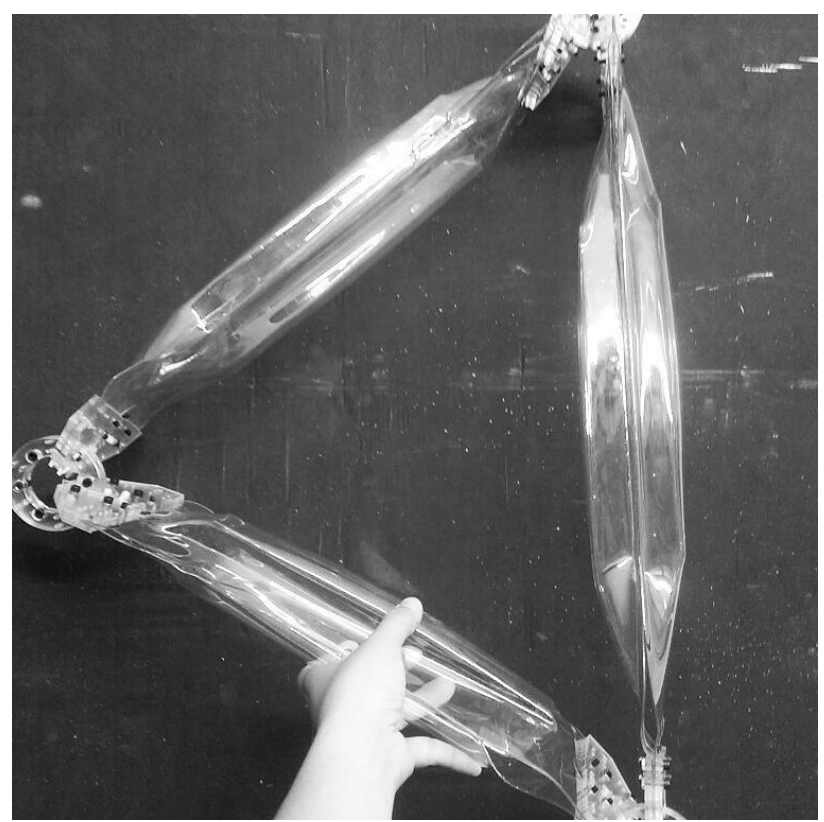

Figure 53: Inflatable unit combination thermoformed with different thicknesses. Source: authors.

\section{DISCUSSION}

In this study, three different methods and tools were used to try to make various aeration units, from simple geometric totems to complex totems that must be created by parameterizing software, and because of the new method. It can be produced smoothly with the machine, and it can't be simulated in the computer.

After this process, and then find out the construction method and the logic of the manufacturing, the noninflated area with different angles can be used to generate the inflatable unit with different corners and structures to combine a very exciting inflatable body. Finally, this method
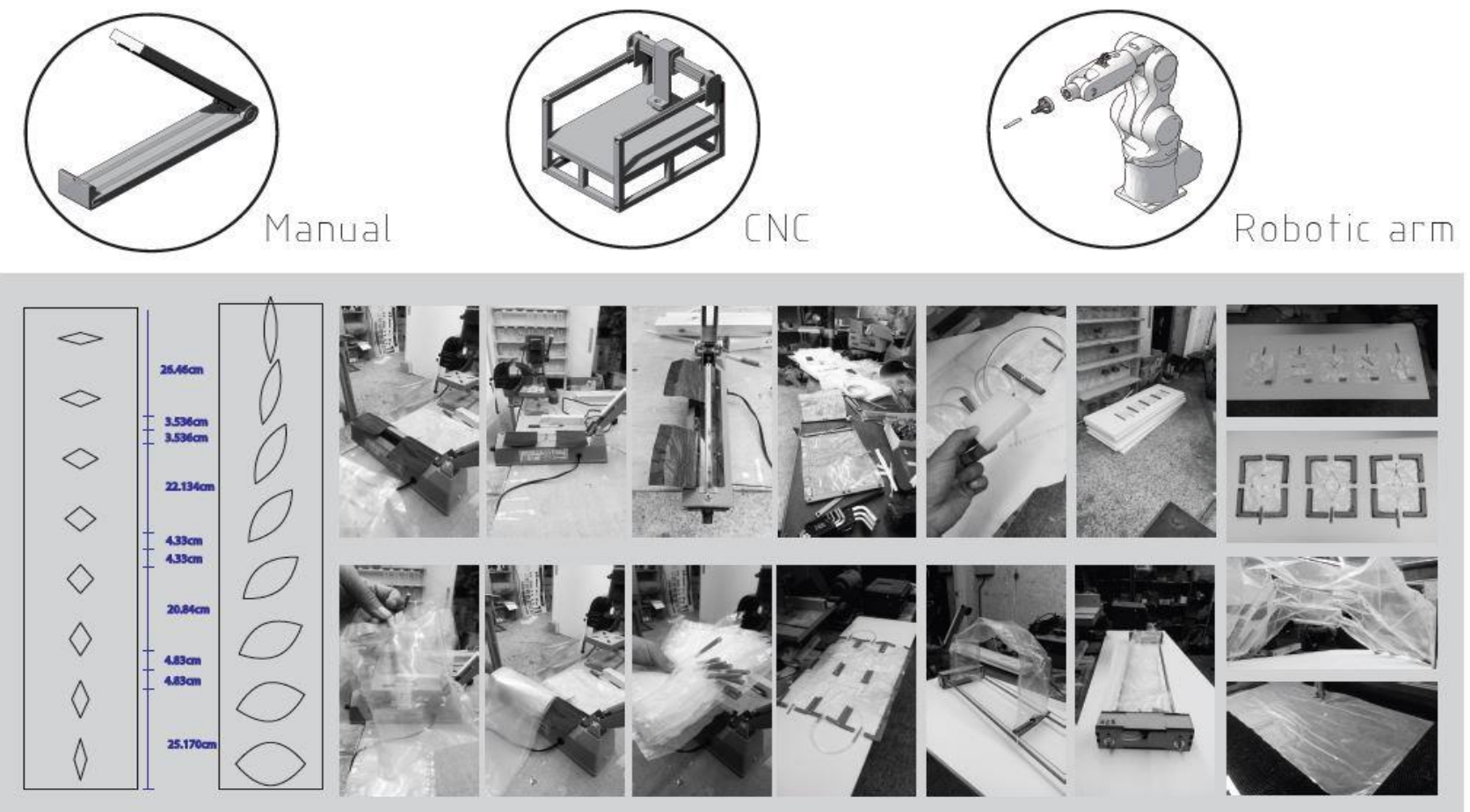

Figure 44: Three methods of construction and their applications. Source: authors. 


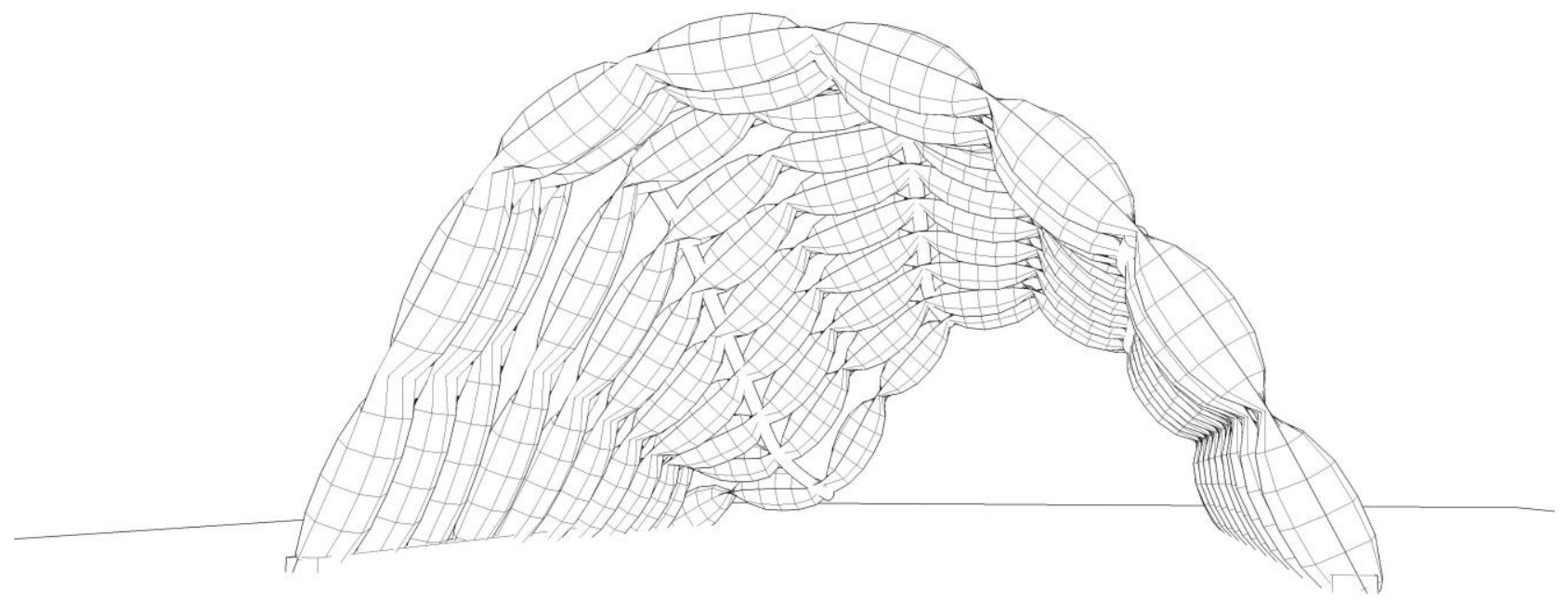

Figure65: The path calculated by the parameterized software and the digital finished product (only in curve). Source: authors.

is also used to manufacture. A simple structure that can be angled after inflation can be achieved by designing a design of the inflation path(Figure 15).

This kind of building is not only well-received, structurally strong, transparent, and easy to carry, it is very suitable for the design of the exhibition hall, or an alternative temporary shelter when the disaster occurs urgently.

Future applications are larger and broader. The manufacturing process and experiments are also tested at the same time with a large-scale structure manufacturing and design (Figure 16) to establish the feasibility of the study for construction and manufacturing.

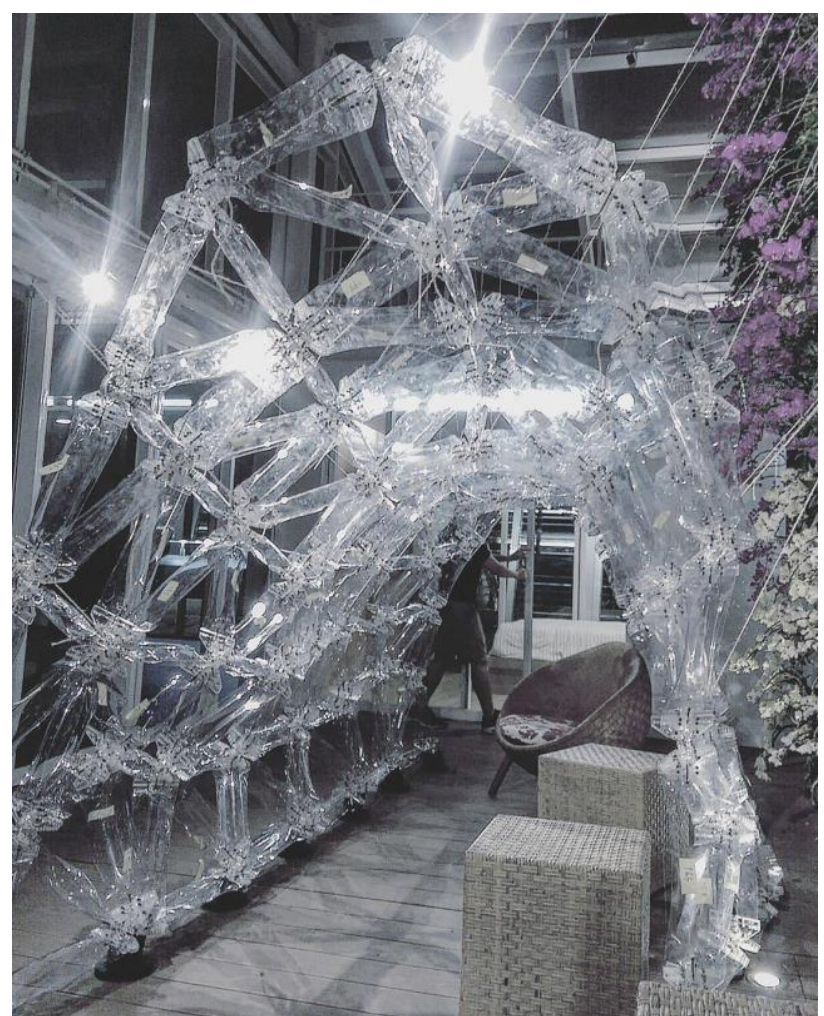

Figure 76: the final pavilion built in the house. Source: authors.

\section{REFERENCES}

[1] Jifei Ou \& Mélina Skouras \& Nikolaos Vlavianos \& Felix Heibeck \& Chin-Yi Cheng \& Jannik Peters \& Hiroshi Ishii (2016). aeroMorph - Heat-sealing Inflatable Shape-change Materials for Interaction Design

[2] Olivier Béthoux (2008).

Groundplan, nomenclature, homology, phylogeny, and The question of the insect wing venation pattern

[3] Harpreet Sareen \& Udayan Umapathi \& Patrick Shin \& Yasuaki Kakehi \& Jifei Ou \& Hiroshi Ishii \& Pattie Maes. (2014). Printflatables: Printing Human-Scale, Functional and Dynamic Inflatable Objects 3D printing of textile-based 